Portland State University

PDXScholar

Engineering and Technology Management

Faculty Publications and Presentations

$11-2006$

\title{
Predicting U.S. Jet Fighter Aircraft Introductions from 1944 to 1982: A Dogfight Between Regression and TFDEA
}

Lane Inman

Portland State University

Timothy R. Anderson

Portland State University, tim.anderson@pdx.edu

Robert R. Harmon

Portland State University, harmonr@pdx.edu

Follow this and additional works at: https://pdxscholar.library.pdx.edu/etm_fac

Part of the Engineering Commons

Let us know how access to this document benefits you.

\section{Citation Details}

Inman, Lane; Anderson, Timothy R.; and Harmon, Robert R., "Predicting U.S. Jet Fighter Aircraft Introductions from 1944 to 1982: A Dogfight Between Regression and TFDEA" (2006). Engineering and Technology Management Faculty Publications and Presentations. 43.

https://pdxscholar.library.pdx.edu/etm_fac/43

This Post-Print is brought to you for free and open access. It has been accepted for inclusion in Engineering and Technology Management Faculty Publications and Presentations by an authorized administrator of PDXScholar. Please contact us if we can make this document more accessible: pdxscholar@pdx.edu. 


\title{
Predicting U.S. Fighter Jet Introductions from 1944 to 1982: \\ A Dogfight Between Regression and TFDEA
}

\author{
Lane Inman ${ }^{1}$, Timothy R Anderson ${ }^{2}$, Robert Harmon ${ }^{2}$ \\ ${ }^{1}$ VMware, USA \\ ${ }^{2}$ Department of Engineering and Technology Management, Portland State University, USA
}

\begin{abstract}
Since its inception in 2001, technology forecasting using data envelopment analysis (TFDEA) has been used with a number of applications. This paper presents a formal comparison of TFDEA to a previously published application from Technological Forecasting and Social Change by Joseph Martino. Using the data and Martino's multiple regression model, we compare results obtained from TFDEA to those previously published. Both techniques predict the first flights of fighter jets introduced between 1960 and 1982 by using the first flights of aircraft introduced between 1944 and 1960. TFDEA was found to better predict the first flight dates than the forecast using multiple regression. These results indicate that TFDEA may be a powerful new technique for predicting complex technological trends and time to market for new products.
\end{abstract}

\section{INTRODUCTION}

Technology forecasting using data envelopment analysis (TFDEA) was first introduced as a quantitative approach for technology forecasting in 2001 [4]. Since its PICMET '01 introduction, it has been applied to a variety of industries including enterprise database systems, microprocessors, hard disk drives, and portable flash storage [3, 10].

This paper uses TFDEA to revisit a classic paper by Joseph Martino from Technological Forecasting and Social Change, comparing two different technology forecasting techniques' ability to predict the date of the first flight for U.S. fighter aircraft from 1944 to 1982 [13]. The two techniques used in the original paper were a scoring model and the regression based approach that is used in this paper. Martino concluded that the two techniques performed approximately the same but preferred the scoring model's results, in part due to its ability to handle more factors. To make a meaningful comparison of technology forecasts, we divided the dataset into two parts: before and after a fixed point in time - in this case, 1960. This allows the earlier part of the dataset (pre-1960) to be used to predict the later part (post-1960) using only information available at the time of the forecast in 1960. Since this "hold-out" model uses only data prior to 1960, it would be difficult to discover an expert with only knowledge of the 1960's without being influenced by those events afterwards. In fact, one strength of TFDEA is its 
ability to take into account "shifting" preferences [10]. Unfortunately this precludes the use of the scoring model since it requires one or more experts from whom to elicit weights on attributes and by definition, an expert will have detailed knowledge of what happened after 1960.

\section{BACKGROUND}

Martino has emphasized that a forecast's validity should be judged in so far as it helps a decision maker to make a correct and timely decision [12]. Therefore, it is reasonable to build a model based on what is known and then evaluate it based upon future data. This gives rise to the scenario underlying this comparison. For this paper, one may take the position of a U.S. defense aviation analyst in 1960. In the midst of the Cold War and the era's military conflicts, fighter aircraft were undergoing rapid development and adapting to changing mission requirements. Based upon needs analysis, the specifications of the seven fighter aircraft to be developed over the next 22 years can be used to predict when these aircraft might be expected to conduct their first flights. Without modification, this could be used from the competitive perspective of a Soviet military strategist attempting to predict when new U.S. aircraft with advanced technology may be introduced.

Predicting a new product's release date can influence the project's overall cost and return on investment. It is also of strategic importance since early release may be associated with increased long-term profits. Predicting a new product's release date is important whether you are in the high technology industry or the defense industry and has been the subject of voluminous work. These issues are explored in greater detail in the NPD literature and influential works include [5, 6, 14, 19, 20].

\section{REGRESSION-BASED MODEL AND RESULTS}

Regression is an accepted model for both time-based and causal-based technology forecasting [17]. Martino [13] credits Alexander and Nelson [1] for making the strong connection between regression and technology forecasting. Alexander and Nelson referred to this approach planar tradeoff surface, which makes apparent the interpretation of the model. To make this paper more approachable for a general reader unfamiliar with the variety of quantitative technology forecasting techniques, this will be referred as a regression-based technology forecast.

In this work, the same regression model as Martino [13] is used in terms of independent variables but limited our data set to the 19 U.S. fighter jets with first flights prior to 1960. Martino's regression model used only four of the seventeen potential characteristics due to the limited number of aircraft (data points) and the high correlation between these 
characteristics (independent variables), which would have caused significant regression problems. The four independent variables were selected based on a combination of application expertise and stepwise regression.

As shown in Table I, the regression model was statistically significant and as shown in Table II, the coefficients were consistent with those obtained by Martino using the full 26 fighter jet data set [13]. As would be expected, the results differ but the magnitude and signs of the coefficients.

TABLE I

\begin{tabular}{ll} 
REGRESSION FIT STATISTICS \\
$\mathrm{R}^{2}$ & 0.943220 \\
Adjusted $\mathrm{R}^{2}$ & 0.926998 \\
Standard Error & 3.178914 \\
Observations & 19 \\
\hline
\end{tabular}

TABLE II

REGRESSION MODEL

\begin{tabular}{|c|c|c|c|c|c|}
\hline & \multirow{2}{*}{$\begin{array}{c}\text { Martino's } \\
\text { Original } \\
\text { Regression } \\
\text { Coefficients } \\
\end{array}$} & \multicolumn{4}{|c|}{ Regression Results Using Only pre-1960 Aircraft } \\
\hline & & $\begin{array}{l}\text { Regression } \\
\text { Coefficients }\end{array}$ & $\begin{array}{c}\text { Standard } \\
\text { Error } \\
\end{array}$ & $t$ Stat & P-value \\
\hline Intercept & 1938.740 & 1937.44 & 2.42652 & 798.4 & $5.2 \mathrm{E}-34$ \\
\hline Maximum Mach number & 5.431 & 6.89407 & 1.81625 & 3.796 & 0.001967 \\
\hline Mean flying hours between failures & 4.036 & 4.02832 & 1.04935 & 3.839 & 0.001807 \\
\hline Payload (lbs.) & 0.002 & 0.00269 & 0.00100 & 2.698 & 0.017311 \\
\hline Range of BVR missiles (miles) & 0.178 & 0.34162 & 0.10310 & 3.313 & 0.005124 \\
\hline
\end{tabular}

\section{TFDEA-BASED MODEL AND RESULTS}

\section{A. Modeling Process}

The methodology to track the technological rate of change (RoC) using TFDEA is illustrated in (1). For every potential technological frontier period, $t_{f}$, from start time, $t_{0}$, in time $T(1)$, data is analyzed. A technological index at product $k$ 's time of release, $\phi_{t_{k}}$, is calculated using (3) - (8) by analyzing each product $k$ in $1 . . n$ products which are introduced on or before $t_{f}(2)$. The linear program, (3) - (8), is a variable returns to scale (VRS) output-oriented DEA model. The variable $x$ represent $1 . . s$ structural characteristics and $y$ I a set of $1 . . m$ functional performance attributes. The process compares each product is compared to a weighted mix of its peers indicated by $\lambda_{\mathrm{k}, \mathrm{j}}$. Those products that are found radially efficient with DEA at time $t_{f}, \phi_{k}=1.0$, are declared state of the art (SOA) and used to calculate the technological rate of change. 
When a product that was SOA, $\phi_{k}=1$, upon introduction is no longer SOA, its technological index at time $t, \phi_{k}^{t}$,

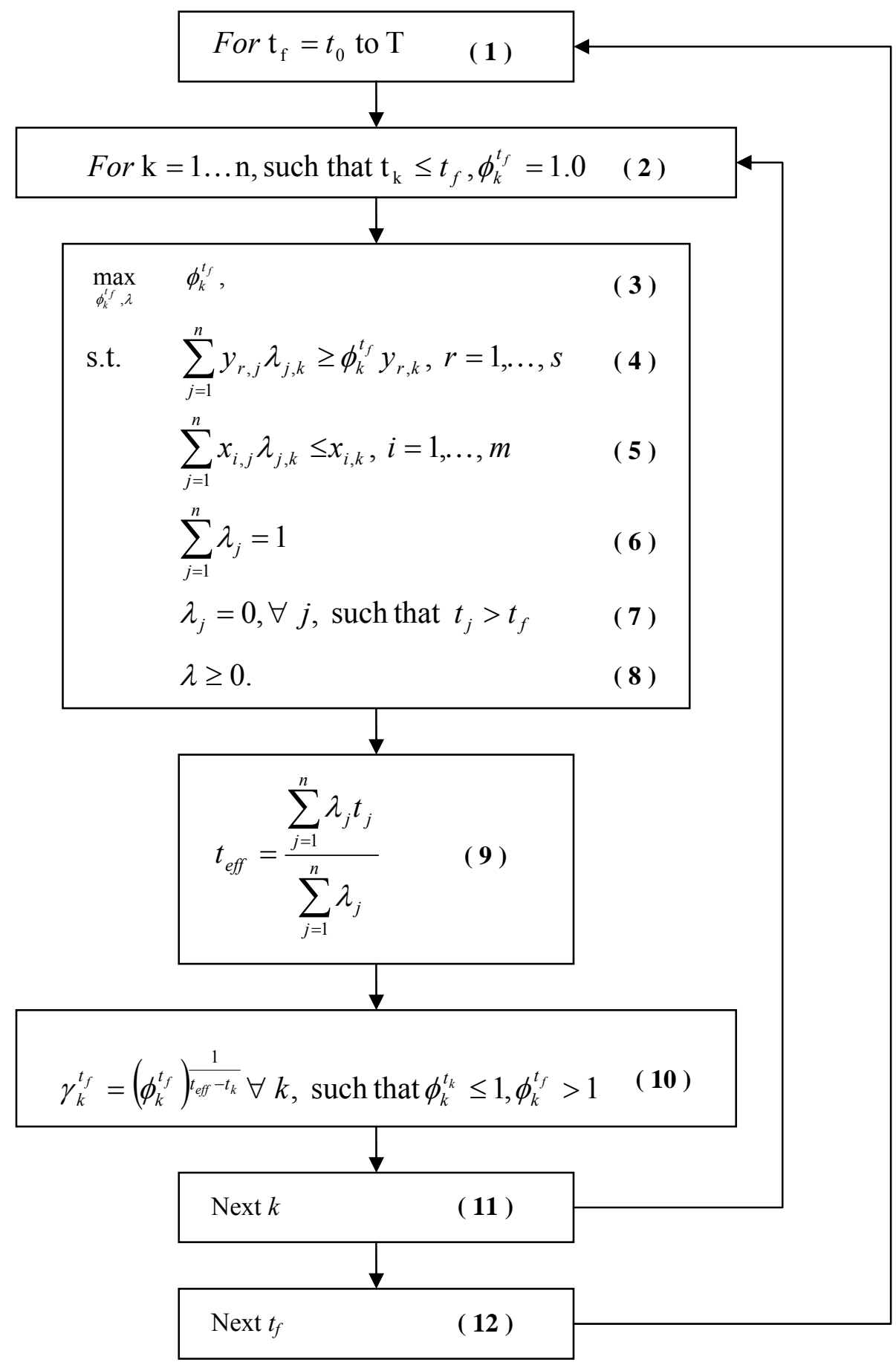

Figure 1 - Calculating the RoC 
is no longer unity and the time of the current SOA is used to determine the effective time that the current benchmark was set (9). At any given point in time, the $\mathrm{RoC}$ for each product is calculated using the new index is used in conjunction with the effective time, $t_{e f f}$, between $t_{k}$ and the region of the SOA against which it is compared. This is then used to calculate the mean effective RoC for that product (10). During each period, the mean technological RoCs for all formerly SOA product $k$ at time $t, \gamma_{k}^{t}$, may then be used in two ways. For more information on implementing TFDEA as well models incorporating other variations of DEA models, the reader is referred to Inman [10] which provides a step-by-step process and the mathematical details for conducting a TFDEA.

\section{B. Input-Output DEA Model of Fighter Jets}

The four independent variables used by Martino all represent "goods" in that higher values correspond to a better performing and more advanced fighter jet, holding everything else constant. Therefore they were designated as outputs in terms of a DEA model. There was no characteristic analogous to an input so a constant value of 1.0 was used to reflect each aircraft as being able to successfully fly.

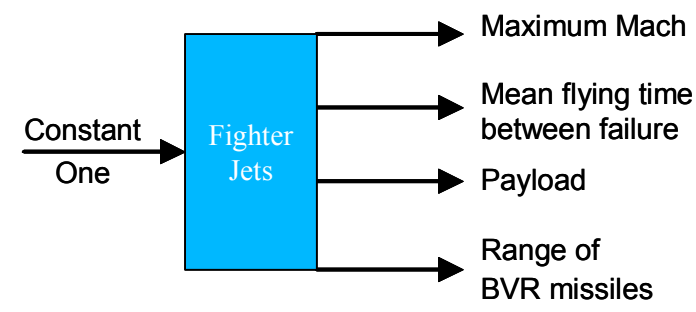

Figure 2 - Basic input-output model of US fighter jets

\section{Forecasting the Technological Rate of Change Using TFDEA}

TFDEA was used to estimate a rate of technology change from 1944 through 1959. Conceptually, this is done by using the first U.S. fighter jet, the F80, in 1944 to establish a technology frontier. The next jet, the F84, which first flew in 1946, is then compared against the 1944 frontier. If the new jet extends the efficiency frontier, the amount by which it extends the efficiency frontier is used to estimate a rate of technology change. Since two years have passed between the 1944 frontier and the 1946 frontier change caused by the F84, the annual rate of change estimate is the square root of the distance metric. If the F84 had not exceeded the technology frontier set by the F80, it would have been considered a non-competitive product and that did not affect the rate of change estimate. 
This process is repeated for each aircraft from the F86 in 1947 to the F5A in 1959 resulting in a series of annual rate of technology change estimates that can be used to forecast the first flight of future state of the art aircraft.

\section{Predicting the year of an aircraft's first flight}

This scenario posits a military analyst at the beginning of 1960 examining the specifications of the upcoming seven planes (F4E, F14, F5E, F15, F16, F18, and F20) as being needed over the upcoming 22 years and attempts to predict their first flights. To do this, the distance of these seven future aircraft is measured from the 1959 state of the art aircraft. This is done using DEA super-efficiency. This super-efficiency is simply the same as (3)-(8) for $t_{f}=1959$. The objective function value for each of the seven aircraft is denoted as $\phi_{k}^{1959, S E}$ to reflect the super-efficiency score for each of the seven fighter jets, $k$. In the super-efficiency case, a value of $\phi_{k}^{1959, S E}<1.0$ indicates that the fighter jet, $\mathrm{k}$, exceeds the performance of the start in in 1959 and the smaller the value, the more it exceeds the performance. Given the rate of change, $\bar{\gamma}$, it is a simple matter to calculate when this expected level of performance should be achieved as shown in (13).

$$
t_{k, \text { expected }}=1959+\frac{\ln \left(\frac{1}{\phi_{k}^{1959, S E}}\right)}{\ln (\bar{\gamma})}
$$

\section{COMPARISON OF TECHNOLOGY FORECASTS}

Figure 3 provides a clear visual comparison of the technology forecasts. Aircraft falling on the diagonal line would have conducted their first flight at exactly the time predicted given their documented specifications. Aircraft lying above the line conducted their first flight earlier than the technology forecast(s) predicted. Aircraft falling below the line conducted their first flight later than the technology forecast predicted. From a new product development (NPD) perspective, these aircraft would represent underperforming products that were late to market.

Each of the 7 aircraft from 1960 to 1982 has two values falling on the same vertical line since the same actual plane had the same actual year of first flight. The diamonds in figure 4 represent the regression-based technology forecast of the year of the first flight for a particular plane. Similarly, the circles represent the TFDEA-based forecast. This figure can be interpreted as a plot of $Y$ vs. $\hat{Y}$ and the distances from this line can be interpreted as residuals. As would be expected, the regression-based forecasts are quite accurate for aircraft prior to 1960 since this data was used for building the regression forecast as well as the TFDEA forecast. 


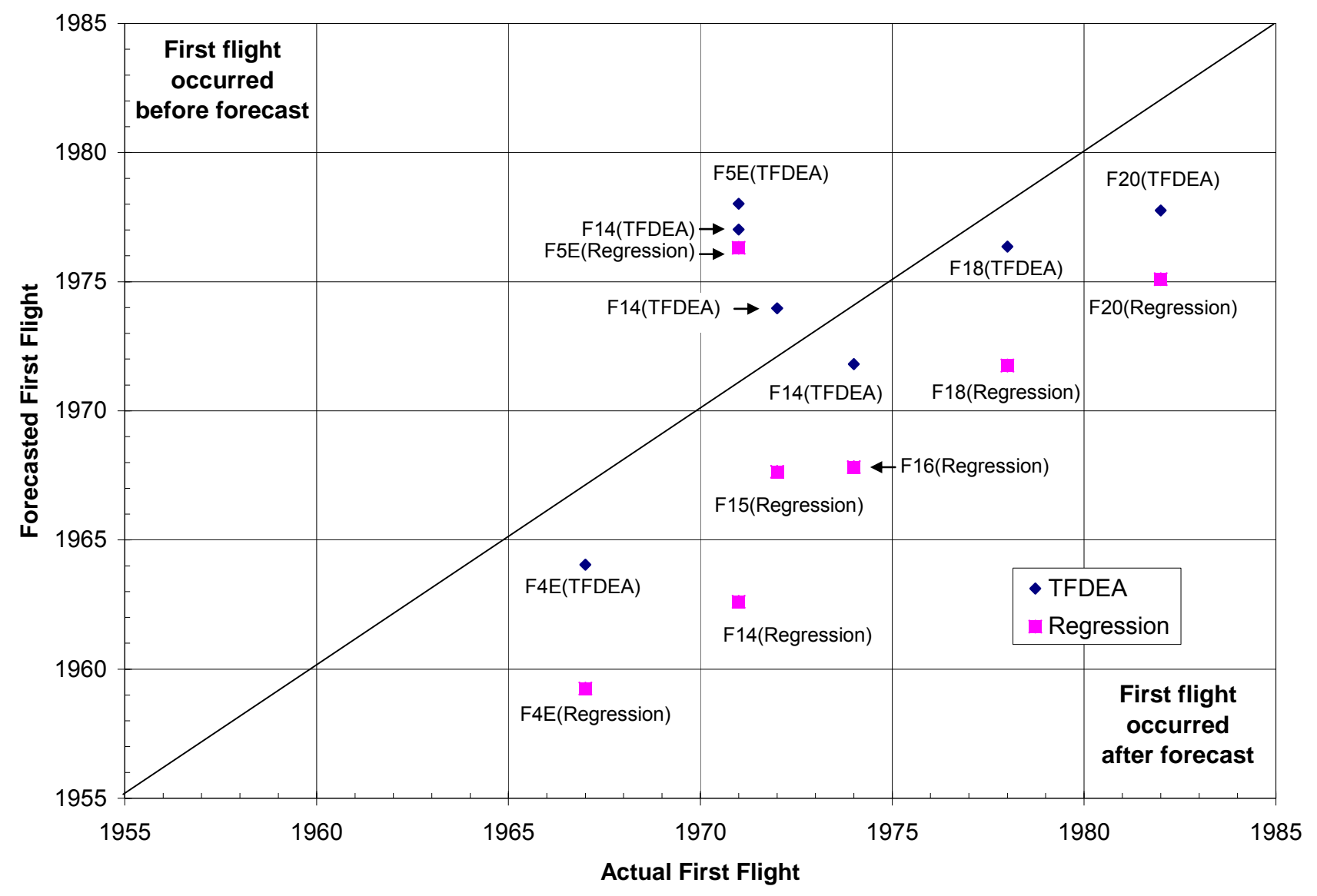

Figure 3 - Predicted vs. Actual First Flights

Two common methods of evaluating forecasts are by comparing the absolute deviations and the squared errors. Both methods give equal weight to errors of both under-predicting and over-predicting. The predicted release dates of the seven aircraft are given in Table III and show that TFDEA gave more accurate forecasts of first flight dates. It should be noted that using the current model, multiple optima exist within TFDEA. While this would not affect the objective function $(\phi)$, it can cause alternate values of $\lambda$ which would then affect $t_{\text {eff }}$ as denoted in the following table. Further constraints to the formulation will be visited in future research. 
TABLE III

COMPARISON OF FORECASTED FIRST FLIGHTS FOR POST-1960 US FIGHTER JETS

TFDEA Intermediate Results Forecasted First Flights

\begin{tabular}{cccccc} 
& $\begin{array}{c}\text { Actual } \\
\text { First Flight }\end{array}$ & $\phi_{k}^{1959, S E}$ & $t_{\text {eff }}$ & TFDEA & Regression \\
\hline F4E & 1967 & 0.5859 & 1956.06 & 1964.04 & 1959.25 \\
F14 & 1971 & 0.2000 & $1953.00^{*}$ & $1977.02^{*}$ & 1962.61 \\
F5E & 1971 & 0.2000 & $1954.00^{*}$ & $1978.02^{*}$ & 1976.31 \\
F15 & 1972 & 0.3000 & 1956.00 & 1973.97 & 1967.64 \\
F16 & 1974 & 0.3285 & 1955.19 & 1971.81 & 1967.82 \\
F18 & 1978 & 0.2622 & 1956.38 & 1976.36 & 1971.75 \\
F20 & 1982 & 0.2419 & 1956.58 & 1977.76 & 1975.10 \\
* indicates that the results may differ due to multiple optima of the $\lambda$ variables in \\
the DEA linear program for this aircraft.
\end{tabular}

Having only seven aircraft instances in our sample limits the resolution of our statistical hypothesis testing, but we can still examine their significance with appropriate caveats. These results are summarized in Table IV. While there is evidence that TFDEA outperforms the regression-based technology forecast in this application, it must be interpreted carefully. The pvalues are relatively high at $7 \%$ and $13.7 \%$ for the absolute deviation and squared deviation metric-based hypotheses respectively. These results might be considered weak for a sample drawn from a large population but given that we have a full population of fighter jets rather than a sample these results are compelling. This forecasting situation is quite challenging in that we used only 16 years of data (1944 to 1959) in order to extrapolate 23 years into the future (1960 through 1982.)

TABLE IV

$\begin{array}{ccc}\text { Hypotheses } & \text { t stat } & \mathrm{p} \text {-value } \\ H_{0}: \mu_{\text {Regression }}^{\text {Absolute Deviation }}-\mu_{\mathrm{TFDEA}}^{\text {Absolute Deviation }} \leq 0 & & 0.0085 \\ H_{a}: \mu_{\text {Regression }}^{\text {Absolute Deviation }}-\mu_{\mathrm{TFDEA}}^{\text {Absolute Deviation }}>0 & 3.265 & (0.85 \%) \\ H_{0}: \mu_{\text {Regression }}^{\text {Squared Deviation }}-\mu_{\text {TFDEA }}^{\text {Squared Deviation }} \leq 0 & & \\ H_{a}: \mu_{\text {Regression }}^{\text {Squared Deviation }}-\mu_{\text {TFDEA }}^{\text {Squared Deviation }}>0 & 2.921 & 0 . .0133 \\ \end{array}$

\section{Discussion of results}

The deviations (or residuals) are consistent with those obtained by Martino [13] and the basic model of what is measured and what is not measured is the same as Martino's model. Therefore, his explanations and discussion regarding the reasons for residuals are equally valid for TFDEA. 
For example, Martino noted that the F5E was released earlier than predicted using both his regression-based and scoring-based approaches. We also found the F5E to be released earlier than expected, and Martino's discussion applies equally well here. On the basis of the four characteristics used, the F5E looks impressive but these impressive characteristics were achieved by sacrificing range - the F5E had the shortest range (120 miles) of any of the 19 planes examined. Since range was not included in the regression model and therefore the TFDEA model, there was no "penalty" for the F5E's poor performance on this metric.

Martino concludes that the regression-based forecast and the scoring model provide similar quality of forecasts but that there are tradeoffs associated with them. For example, the scoring-based approach has a major advantage of being able to include a much larger number of characteristics than the regression-based approach. A significant disadvantage of the scoringbased approach is its reliance on an expert and the sensitivity of the results to their elicited weights. On the basis of examining the individual aircraft that suffered from poor predictions, he concluded with a slight preference for the scoring model's ability to incorporate more information. As previously noted, however, scoring models are based on expertise at the time of implementation. So, in cases such as fighter jets, those trade-offs are likely, and did, change over the years.

TFDEA is built on an econometric technique, DEA, that is fundamentally different from regression and does not share regression's problems with multicollinearity [2]. Therefore, it would be possible that more independent variables (inputs and outputs in DEA terminology) than the four selected by Martino could be used in this TFDEA study and thereby potentially recognizes problems such as the F5E's limited range. Like regression, DEA, and therefore TFDEA, requires a large number of observations (in this case aircraft) relative to the number of independent variables. While this might prevent us from enriching the model with some of the thirteen omitted aircraft characteristics, there are well-accepted approaches to mitigate these problems in DEA by use of weight restrictions that could be used in TFDEA [10]. Martino's weights from the scoringbased approach could be potentially used as starting points in setting weight restrictions in the TFDEA model.

The post-1982 era of fighter jet technology has undergone significant change with fewer new aircraft development projects. As would be expected, the basic input output model should also be updated to reflect the decreasing emphasis on dogfight tactics. Ironically, one factor that stands out for its absence is stealthiness and would probably need to be added to a model for post-1982 fighter jets. This could be accounted for by including a measure of RADAR profile but could make data collection more difficult for security purposes.

While this study focused on U.S. fighter jet technology, similar analyses could be conducted for other countries. Also, it would be possible to include more derivative aircraft. 


\section{Future Research}

TFDEA has potential to contribute to future research in three areas based on recent PICMET studies. These areas include the fuzzy front-end of NPD, evaluating NPD success, and technology roadmapping.

One challenge in the fuzzy front-end of NPD is setting realistic, marketable, and competitive design targets. Jetter [11] used fuzzy cognitive maps while Petersen and Yoder [15] used conjoint analysis. TFDEA would not supplant these techniques but could help test the feasibility of targets based on the expected date of release.

Many researchers have examined the factors that affect NPD success. Grant, et al, [9] examined the schedule delays in 22 weapon system development programs. Reilly, et al., [18] analyzed the impact of empowerment and its interaction with various sources of uncertainty in NPD and found that empowerment was associated with increased speed. However, measuring NPD speed is always a challenge since in some analyses it is compared against the original product proposal's release date. In cases where these release dates might be unrealistically optimistic to get a project funded, an alternative way of setting an expected release date may be useful. TFDEA could provide these alternate release dates and the residuals could then be viewed as another metric of schedule delay and NPD success (or the lack thereof). This would correspond to examining the reason why certain aircraft development projects fell in the lower right triangle of Figure 4.

Lastly, clarification between TFDEA, technology roadmapping and technology development envelope procedures can be explored. TFDEA is well-suited to setting NPD targets without specifying the particular technologies that required for a new product to deliver that performance. In 2002, Anderson et al. [3] used TFDEA to forecast microprocessor performance. One of the inputs used was power consumption. Achieving the desired level of performance could require significantly more power and therefore increased heat dissipation beyond the ability of current technologies. In 2003, Gerdsri and Kocaoglu [8] introduced TDE and applied it to electronic cooling technology in computer servers. The technology development envelope could then be used to help form a company's technology roadmap. Gerdsri further formalized TDE in recent work [7]. Phaal, et al., [16] provides a comprehensive introduction to technology roadmapping.

\section{CONCLUSION}

This comparison of technology forecasts was consistent with Martino's emphasis on the need for having a timely and beneficial impact on decision makers. The TFDEA results were statistically more accurate, and both methods only relied on data available to the hypothetical decision maker in 1960. 
These preliminary results indicate that TFDEA may be a useful approach for predicting a product's date of release and thus provide an accurate estimate of time to market for complex new products. This information could then be used to assist in a variety of areas of NPD research.

\section{REFERENCES}

[1] A. J. Alexander and J. R. Nelson, "Measuring technological change: aircraft turbine engines," Technological Forecasting and Social Change, vol. 5, pp. 189-203, 1973.

[2] T. R. Anderson, "Data Envelopment Analysis," in Encyclopedia of Information Systems, vol. 1, H. Bidgoli, Ed.: Elsevier, 2003 , pp. $445-454$.

[3] T. R. Anderson, S. Grosskopf, R. Fare, and X. Song, "Further examination of Moore's Law with data envelopment analysis," Technological Forecasting and Social Change, vol. 69, pp. 465-477, 2002.

[4] T. R. Anderson, K. Hollingsworth, and L. Inman, "Assessing the rate of change in the enterprise database system market over time using DEA," in Technology Management in the Knowledge Era, D. F. Kocaoglu and T. R. Anderson, Eds. Portland: PICMET, 2001, pp. 384-390.

[5] L. Bstieler, "The moderating effect of environmental uncertainty on new product development and time efficiency," Journal of Product Innovation Management, vol. 22, pp. 267-284, 2005.

[6] R. G. Cooper, Winning at New Products: Accelerating the Process from Idea to Launch, 3rd ed. Cambridge, Mass.: Persius Publishing, 2001.

[7] N. Gerdsri, "An analytical approach to building a technology development envelope (TDE) for roadmapping of emerging technologies," in Technology Management: A Unifying Discipline for Melting the Boundaries, D. F. Kocaoglu and T. R. Anderson, Eds. Portland: PICMET, 2005.

[8] N. Gerdsri and D. F. Kocaoglu, "An analytical approach to building a technology development envelope (TDE) for roadmapping of emerging technologies: A case study of emerging electronic cooling technologies for computer servers," in Technology Management for Reshaping the World, D. F. Kocaoglu and T. R. Anderson, Eds. Portland: PICMET, 2003, pp. 380-387.

[9] K. P. Grant, W. M. Cashman, and A. A. Omar, "Schedule delays in new product development: A life-cycle perspective," in Technology Management for Reshaping the World, D. F. Kocaoglu and T. R. Anderson, Eds. Portland: PICMET, 2003, pp. 290-297.

[10] L. Inman, "Technology Forecasting Using Data Envelopment Analysis," in Engineering and Technology Management. Portland: Portland State University, 2004.

[11] A. J. M. Jetter, "Educating the guess: Strategies, concepts and tools for the fuzzy front end of product development," in Technology Management for Reshaping the World, D. F. Kocaoglu and T. R. Anderson, Eds. Portland: PICMET, 2003, pp. 261-273.

[12] J. P. Martino, "Evaluating forecast validity," in A Guide to Practical Technological Forecasting, J. R. Bright and M. E. F. Schoeman, Eds. Englewood Hills: Prentice-Hall, 1984, pp. 26-52.

[13] J. P. Martino, "A comparison of two composite measures of technology," Technological Forecasting and Social Change, vol. 44, pp. 147-159, 1993.

[14] M. McGrath, Product Strategy for High Technology Companies: Accelerating Your Business to Web Speed. New York: McGraw-Hill, 2000.

[15] C. L. Petersen and L. Yoder, "Use of conjoint analysis and design of experiments in designing projection displays," presented at PICMET, Portland, 1999. 
[16] R. Phaal, C. Farrukh, and D. Probert, "Developing a technology roadmapping system," in Technology Management: A Unifying Discipline for Melting the Boundaries, T. R. Anderson, D. F. Kocaoglu, and T. U. Daim, Eds. Portland: PICMET, 2005.

[17] A. L. Porter, A. T. Roper, T. W. Mason, F. A. Rossini, and J. Banks, Forecasting and Management of Technology. New York: John Wiley \& Sons, 1991.

[18] R. R. Reilly, J. Chen, and G. S. Lynn, "Power and empowerment: The role of top management support and team empowerment in new product development," in Technology Management for Reshaping the World, D. F. Kocaoglu and T. R. Anderson, Eds. Portland: PICMET, 2003 , pp. $282-289$.

[19] P. G. Smith and D. G. Reinertsen, Developing Products in Half the Time: New Rules, New Tools: Wiley, 1997.

[20] W. Zangwill, Lightening Strategies for Innovation: How the World's Best Firms Create New Products. New York: Lexington Books, 1993. 